\title{
Thermal-Hydraulic Simulation of Cold Water Spray in a Nuclear Power Plant Containment
}

\author{
Y.Azari ${ }^{b}$ and S.Tashakor ${ }^{*}, \mathbf{a}, \mathbf{b}$ \\ (a) Department of Renewable Energy, Shiraz Branch, Islamic Azad University, Shiraz, Iran \\ (b) Department of Mechanical Engineering, Shiraz Branch, Islamic Azad University, Shiraz, Iran
}

\begin{tabular}{l} 
ARTICLE INFO \\
\hline Article history: \\
Received: $16^{\text {th }}$ May 2021 \\
Accepted: $2^{\text {nd }}$ Sept. 2021
\end{tabular}

\section{Keywords:}

Containment,

Spray,

temperature,

nuclear reactor.

\begin{abstract}
Sprays play an important role in cooling and decreasing pressure inside the containment of nuclear reactor in emergency situations and excessive pressure of containment. When temperature and pressure exceed $120^{\circ} \mathrm{C}$ and 2 bars respectively, the sprays cool the inside of PWR containment. The containment spray system is designed to condense the steam to prevent the occurrence of high pressure and temperature, which could lead to disintegration of containment and the leakage of radioactive material to the environment. In this study a simulation of a concrete tank of the reactor (containment) with 250 sprays is accomplished using Ansys Fluent software (18.2). Multiphase mixture model and k- $\varepsilon$ realizable turbulence model are used to model the reactor. Associated equations are solved using the finite volume method (SIMPLE algorithm with pressure and velocity coupling) in Ansys Fluent software. It is assumed that the flow regime is transient. Results of the thermal-hydraulic function of spraying, which has decreased pressure and temperature, are presented.
\end{abstract}

\section{INTRODUCTION}

Containment systems are used as the last barrier for the unrestrained discharge of radionuclides during a DBAs accident. These systems and their safety components are designed to accommodate the accident environment during DBAs.The containment spray system is a safety system that supplies water for the protection of the core in large break LOCA and other DBA accidents. The temperature of containment is controlled by various cooling systems. The containment spray system is designed to condense the steam to prevent the occurence of high pressure and temperature, which could lead to disintegrtion of containment and as result leakage of radioactive material to the environment.

Spray function in radioactive material is assessed by Lin et al., [1]. Lin assumed that the cover of the fuel rod has been damaged and radioactive material has spread into the ecosystem. Babic et al.,studied the injection of spray into a hot gas atmosphere with heat and mass transfer using TOSQAN. They used a two-fluid approach with Lagrangian description for droplets and an Eulerian one for the gas phase $[2,3]$.
Malet et al., studied the behavior of a single spray in a boiling water reactor using two different codes: ANSYS / FLUENT-CFX (Lagrangian frame) and EDF NEPTUNE-CFD (eulerian frame) [4,5,6]. Malet et al., explained empirical and numerical progress in spray system design and utility in the nuclear power plant in the last decade [7]. Malet et al., simulated a pressurized water reactor with 253 sprays for the safety of the nuclear reactors [8]. They assumed that the reactor core has melted down and hydrogen has been produced. After Fukushima Daiichi nuclear disaster, J Xing et al., designed pressurized water reactor spray so that in circumstances of destroyed water source containing boron, spray system could use other sources for cooling reactor concrete tank in emergency situations[9]. TimoPättikangas et al., performed experiments on single cone sprays in the VTT Technical Research Centre of Finland. In their study, droplet diameter and causes of turbulence in spray particles were simulated in different locations using CFD software [10]. Kaltenbach et al., presented a CFD model for spray cooling which is able to predict heat and mass transfer between cold droplets and hot humid air gas atmosphere. In this study thermalhydraulic water spray behavior with extremely hot steam 
in the reactor containment is analyzed and simulated [11]. If the temperature and pressure of the inner space of containment, which is filled with hot steam, rises sharply, reactor core will melt down and concrete containment along with its equipment will be destroyed. In a chemical reaction, fuel clad is combined with steam and hydrogen is produced. This process and excessive increase in the pressure inside the reactor concrete containment results in reactor containment explosion and spreading radioactive material into the ecosystem. This is what happened at Fukushima Daiichi nuclear disaster. In order to prevent such a disaster, when the pressure inside concrete tank reaches 2 to 2.5 bar and temperature exceeds $120^{\circ} \mathbf{C}[4,5]$, pressure and temperature sensors inside PWR containment receive cool water from refueling water storage tank by sending a signal to reactor central control building, and cooling sprays at the upper part of containment sprinkle cold water on steams and reactor surface. So the superheated steam condenses and turns into a liquid phase. Therefore, temperature and pressure decrease. In Fig. (1). a sample of cooling sprays in reactor containment is shown. Generally, the purpose of cooling sprays is decreasing the temperature and pressure inside reactor containment. The containment spray system is able to take water from the sump if the refueling water storage tank has run out of water.

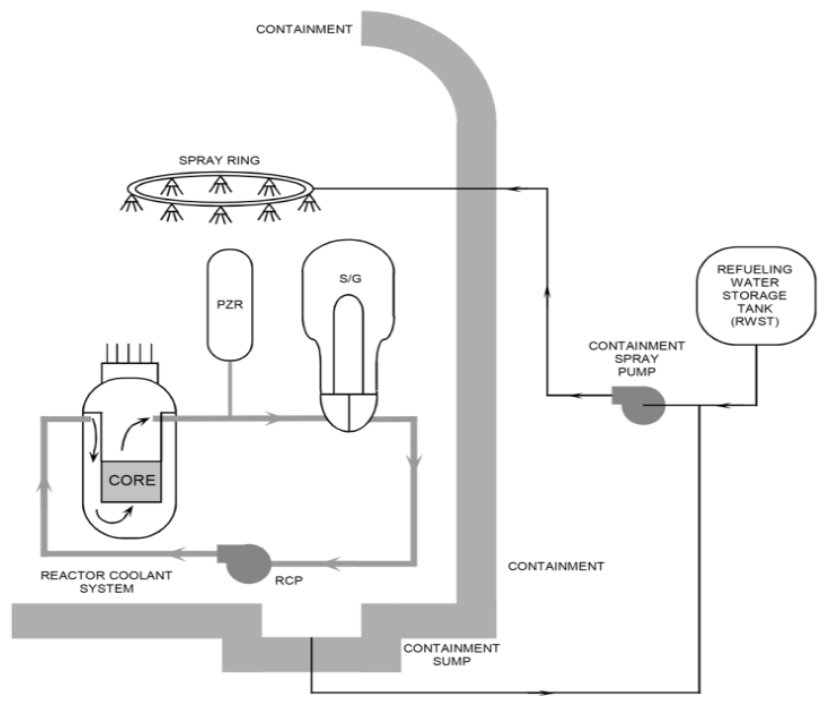

Fig. (1): Sample of cooling sprays in reactor containment

\section{METHODS AND MATERIALS}

ANSYS FLUENT is used to simulate thermalhydraulic spray behavior (in emergency condition) in nuclear power plant containment. In this problem, a 2D model is used. In Fig.( 2) geometry and scales of nuclear reactor containment are presented. This geometry is used as the main template. Due to symmetric geometry at
Ansys Fluent, the symmetrical boundary condition is used to decrease the computational cost. The geometry is illustrated in the spaceclaim cell of Ansys Fluent. Results of the simulation for 250 sprays are presented.

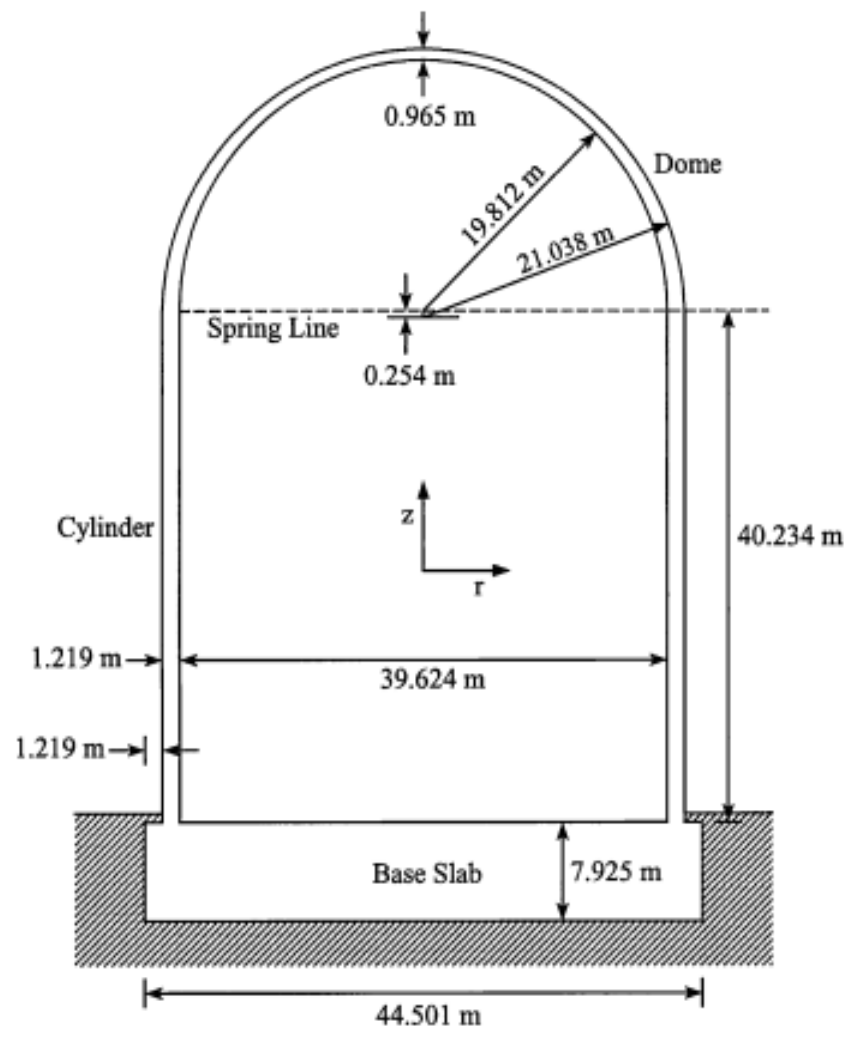

Fig. (2): Geometry and scales of PWR Reactor Containment [12]

\subsection{Boundary Condition}

The boundary condition is one of the most important and determining components for solving equations in Ansys Fluent software. Due to the physics of the matter and flow type in boundaries, boundary condition may vary. Boundary conditions which are used to solve the equations of this problem are as follows:

\section{2-1-1 Velocity Inlet Boundary Condition}

Velocity inlet boundary condition is used to define flow velocity inflow inlets. This boundary condition could be only used in incompressible flow, and its usage in compressible flow leads to non-physical results. This boundary condition is chosen in spray inlets. Here, inlet velocity is assumed constant.

\section{2-1-2 Out Flow Boundary Condition}

In this geometry, outflow boundary condition is used in geometry output (spray outlet and containment outlet). This boundary condition is used in circumstances where there is no information on pressure, velocity, and other variables in the outflow. 


\section{2-1-3 Symmetry Boundary Condition}

The symmetry boundary condition is used to reduce the overall size of the mesh. In order to use this boundary condition, the flow field and geometry must be symmetric. In symmetry boundaries, normal velocity and normal gradient of all variables are assumed to be zero.

\section{2-1-4 Wall Boundary Condition}

No-slip condition on containment walls is assumed.

\section{2-1-5 Separate Phase Boundary Condition}

This boundary condition is chosen as a "reflect" for the walls (in which particles will return by an elastic or non-elastic collision) and "escape" for inlet and out flow boundary conditions (in which particles scape through the boundary).

\section{2-2 Grid Setting}

One of the main components in numerical problem solving is grid setting. The more attention is paid to this step, the more precise and fast the calculations are done. The accuracy of the numerical solution depends on the number of nodes. Using excess nodes, increases needed storage space and computational time. Nodes should be added in a way that they don't affect results. In this study, Ansys Fluent is used to create geometry, mesh and problemanalysis (Fig. 3).

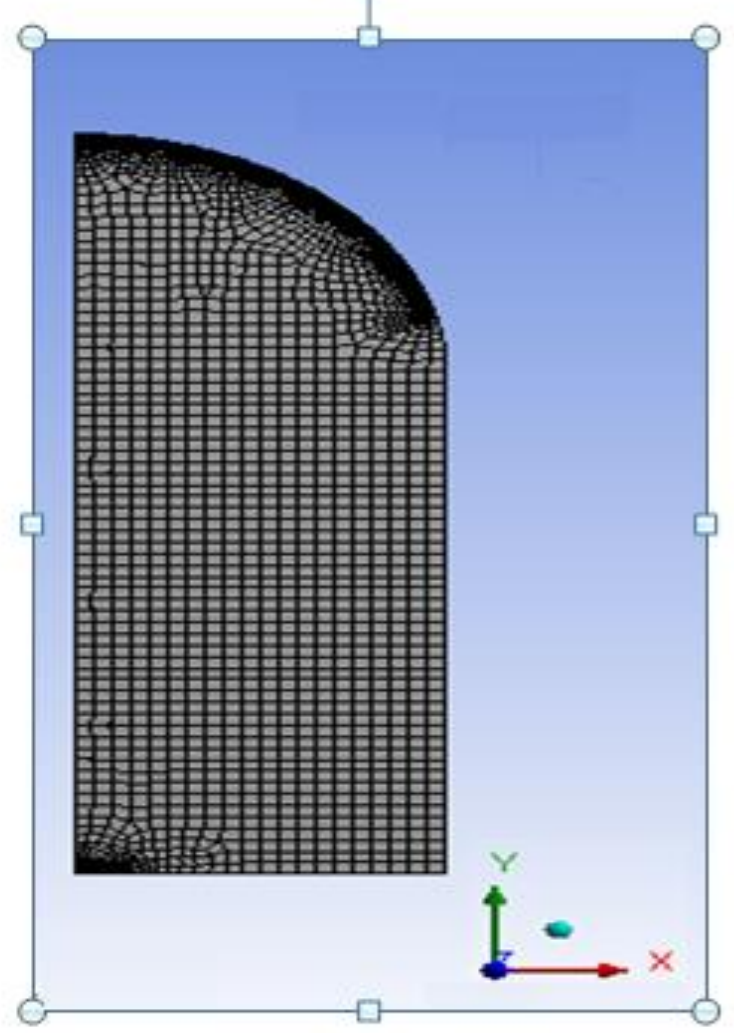

Fig. (3): General view of containment meshing
Geometry is divided into three parts. In the top and bottom parts of the containment, tiny pave and unstructured mesh is used. In the middle part, a structured mesh is utilized. In order to determine the velocity and pressure gradients more precisely, a tiny mesh is used around out flow of sprays.

\section{2-3 Mesh Quality for Geometry}

Ansys software presents information on mesh quality in three parts. The three parameters that must be assessed for each mesh setting include orthogonal quality, skewness, and aspect ratio. The closer orthogonal quality to one and skewness to zero, the better quality of the mesh. The aspect ratio should be between 1 and 5 percent. As shown in Table 1, the quality of produced mesh for this geometry is acceptable. Grid independence is checked in grid setup in the way that by increasing the number of cells more than 571122, no significant change is observed in thermal-hydraulic parameters.

Table (1): Containment mesh quality

\begin{tabular}{cccc}
\hline Mesh Quality & Lowest Amount & $\begin{array}{c}\text { The } \\
\text { Maximum } \\
\text { Amount }\end{array}$ & $\begin{array}{c}\text { Average } \\
\text { Value }\end{array}$ \\
\hline $\begin{array}{c}\text { Orthogonal } \\
\text { Quality }\end{array}$ & 0.46479 & 1 & 0.99733 \\
Skewness & 0.00000000013057 & 0.75027 & 0.014736 \\
\hline Aspect Ratio & 1 & 3.6209 & 1.0237 \\
\hline
\end{tabular}
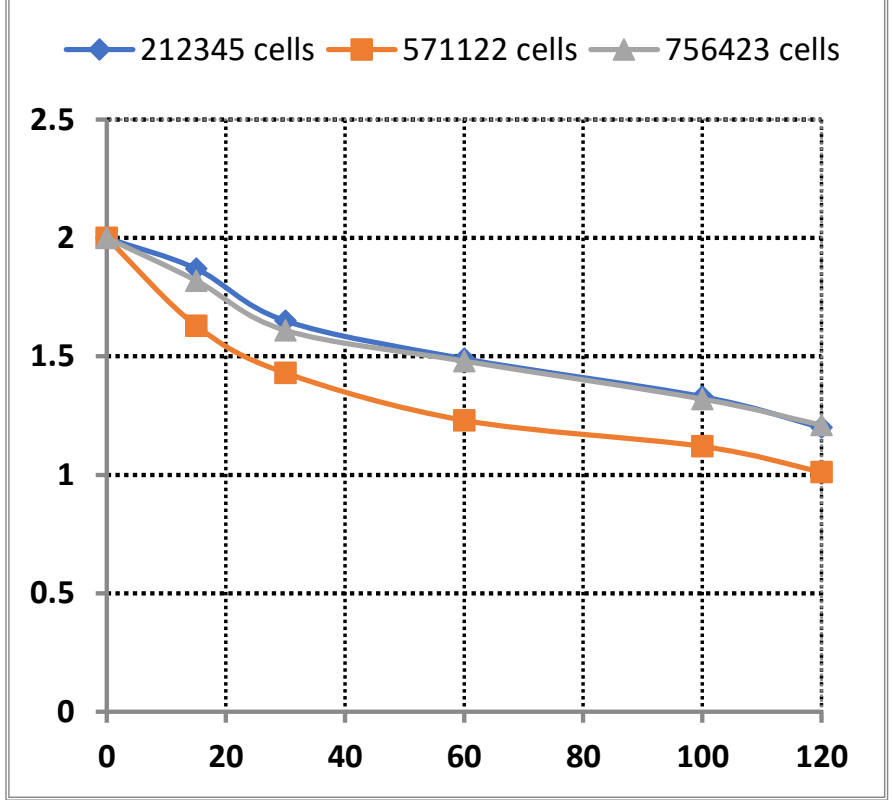

Fig. (4): Mesh sensitivity analysis 


\section{2-4 Assumptions}

In this study, the following conditions and assumptions are assumed:

- Turbulent flow and $\mathrm{k}-\varepsilon$ realizable model are used. Time Transition flow is solved using 0.01 time steps.

- Two phase flow and mixture model are used. Primary and secondary phases are defined as steam and water respectively.

- The temperature inside the reactor containment is $120{ }^{\circ} \mathrm{C}$. Water is sprayed into the reactor containment at a temperature of $20^{\circ} \mathrm{C}$.

- Fluid is incompressible, Newtonian, and viscous.

- Reactor concrete is adiabatic.

\section{.2-5 Spray Modeling}

In this study, k- $\varepsilon$ turbulence model and also standard wall model are selected. To model spray in Ansys Fluent, droplet collision and droplet breakup models are used. Tab model is selected in droplet breakup settings. In the spray setting section, rosin-rammler distribution method is chosen. Particle type is selected as a droplet in spray function simulation due to physics of the matter. Drag spherical law is implemented, in which particles along their path, stay spherical and don't change in shape.

\section{Table (2): Properties of sprayed drops}

\begin{tabular}{cc}
\hline Properties of particles & Numerical values \\
\hline X-velocity $(\mathrm{m} / \mathrm{s})$ & 22.63 \\
y-velocity $(\mathrm{m} / \mathrm{s})$ & 22.63 \\
temperature & 20 \\
Start time $(\mathrm{s})$ & 0 \\
Stop time $(\mathrm{s})$ & 10000 \\
Total flow rate $(\mathrm{kg} / \mathrm{s})$ & 0.668 \\
Min. diameter $(\mathrm{mm})$ & 0.01 \\
Max.diameter $(\mathrm{mm})$ & 1.5 \\
Mean diameter $(\mathrm{mm})$ & 0.713 \\
Spread parameter & 3.5 \\
\hline
\end{tabular}

A homogeneous two phase model is used. The governing equations of the two-phase model in the $\mathrm{z}$-direction are as follows. The equations can be extended in the $\mathrm{x}$ and $\mathrm{y}$ direction $[13,14]$.

\section{2-5-1 Conservation of mass}

$\frac{\partial}{\partial t}\left(A \alpha_{k} \rho_{k}\right)+\frac{\partial}{\partial z}\left(A \alpha_{k} \rho_{k} u_{k}\right)=\Gamma_{\mathrm{k}}$

where $\alpha_{k}$ is the time averaged void fraction of phase $\mathrm{k}$, $\rho_{k}$ is the density of phase $\mathrm{k}, u_{k}$ is the mass-weighted mean velocity of phase $\mathrm{k}$. $\Gamma_{\mathrm{k}}$ represent the mass transfer to phase $\mathrm{k}$ from the various interphase mass transfer, $\mathrm{t}$ is the time per second.

\section{2-5-2 Conservation of momentum}

The rate of creation momentum of phase $\mathrm{k}$ within the control element plus the rate of inflow of momentum is balanced against the sum of forces acting on the phase in the control element.

$$
\begin{aligned}
-A \alpha_{k} \frac{\partial P}{\partial z} \delta z-\tau_{k w} P_{k w} \delta z+\sum_{1}^{n} \tau_{k n z} P_{k n} \delta z \\
-A \alpha_{k} \rho_{k} \delta z g \sin \Theta+u_{k} \Gamma_{\mathrm{k}} \\
=\frac{\partial}{\partial t}\left(W_{k} \delta z\right)+\delta z \frac{\partial}{\partial z}\left(W_{k} u_{k}\right)
\end{aligned}
$$

$\tau_{\mathrm{kw}}$ is the wall shear stress between the phase $\mathrm{k}$ and the channel wall, $\mathrm{P}_{\mathrm{kw}}$ is the contact perimeter between the wall and phase $\mathrm{k}, \tau_{\mathrm{knz}}$ is the $\mathrm{z}$ component of the interfacial shear forces between phase $k$ and phase $n, P_{k n}$ is the contact perimeter between phase $\mathrm{k}$ and phase $\mathrm{n}, \mathrm{W}$ is the mass flow rate.

\section{2-5-3 Conservation of energy}

$$
\begin{aligned}
\frac{\partial}{\partial t}\left(A \alpha_{k} \rho_{k}\right)\left(\varepsilon_{k}\right. & \left.+\frac{u_{k}^{2}}{2}\right)-\frac{\partial}{\partial t}\left(W_{k}\right)\left(i_{k}+\frac{u_{k}^{2}}{2}\right) \\
& =-W_{k} g \sin \Theta+\varphi_{w k} \mathrm{p}_{\mathrm{wk}} \\
& +\sum_{1}^{n} \varphi_{k n} \mathrm{p}_{\mathrm{kn}}+\varphi_{\mathrm{k}} A \alpha_{k}-p A \frac{\partial \alpha_{k}}{\partial t} \\
& +\Gamma_{\mathrm{k}}\left(i_{k}+\frac{u_{k}^{2}}{2}\right)+u_{k} \sum_{1}^{n} \tau_{k n} \mathrm{p}_{\mathrm{kn}}
\end{aligned}
$$

$\varepsilon_{k}$ is the internal energy per unit mass of phase $\mathrm{k}, \varphi_{w k}$ is the heat flow via the channel wall over the perimeterp ${ }_{\mathrm{wk}}, \varphi_{k n}$ is the heat flow via the various interface with the other $\mathrm{n}$ phase, $\varphi_{\mathrm{k}}$ is internal heat generation for phase $\mathrm{k}$ within the control element itself.

\section{RESULT AND DESCUSION}

Here, the results of transient temperature and pressure distribution and particle residence in 250 sprays are presented. Outlet diameters of all sprays are $6.2 \mathrm{~mm}$. 250 spray contours in height of 6 meters from the upper part of reactor tank (first plan) in time intervals of 10 , 40,90 , and 120 seconds and 250 spray contours in height of 20 meters from the upper part of reactor tank (second plan) in time intervals of $10,30,60$, and 97 seconds are presented. 


\section{3-1 Particle Residence Contour}

The time contour of sprayed particles' residence position is shown in Figs. 5. and 6. Heat exchange of cold water sprayed with containment superheated steam is observed at the top of the containment in the first moments of system operation. Due to the evaporation of the sprayed cold water particles, it is not possible to reach the lower parts of the chamber in the initial moments of cold water injection.

As seen at 120 seconds in the first plan and 90 seconds in the second plan, sprayed water fills the entire reactor containment.

\section{3-2 Static Temperature Distribution}

Spray function plays an important role in decreasing temperature inside reactor containment in emergency situations. Flow temperature distribution contour is shown in Figs. (7. and 8). Water is sprayed into the reactor containment at a constant temperature of $20 \mathrm{C}$. Initially, the temperature inside the reactor concrete tank is $120 \mathrm{C}$. Temperature inside the containment is decreased by spray system activation. In order for sprayed particles to fill the entire tank and to cause a drop in temperature, 120 seconds are needed in the first plan and 97 seconds in the second. Spray function effectiveness in reducing concrete tank temperature is noticeable.

\section{3-3 Static Pressure Distribution Contour}

When the containment pressure reaches 2 to 3 bars in the nuclear light-water reactor, sprays start functioning to reduce the pressure. In this problem, containment pressure for spray system activation is defined as 2 bar. As illustrated in the Fig.(9), the average pressure in the containment decreases in both simulated models.

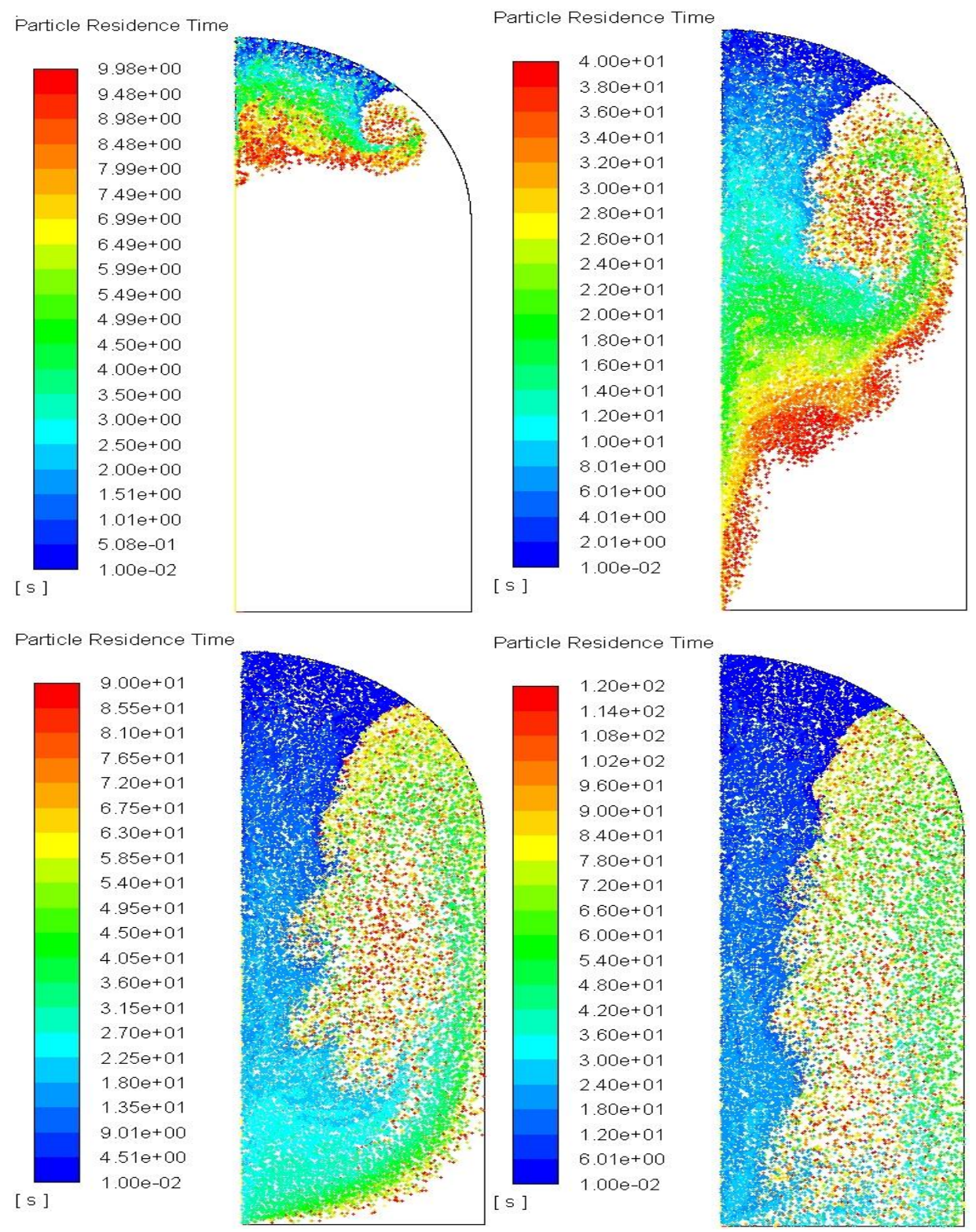

Fig. (5): Time contour of sprayed particles' residence position in time intervals of $10,40,90$, and 120 second related to the first plan 
Particle Residence Time

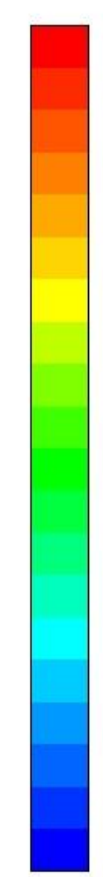

$$
\begin{aligned}
& 9.98 \mathrm{e}+00 \\
& 9.48 \mathrm{e}+00 \\
& 8.98 \mathrm{e}+00 \\
& 8.48 \mathrm{e}+00 \\
& 7.99 \mathrm{e}+00 \\
& 7.49 \mathrm{e}+00 \\
& 6.99 \mathrm{e}+00 \\
& 6.49 \mathrm{e}+00 \\
& 5.99 \mathrm{e}+00 \\
& 5.49 \mathrm{e}+00 \\
& 4.99 \mathrm{e}+00 \\
& 4.50 \mathrm{e}+00 \\
& 4.00 \mathrm{e}+00 \\
& 3.50 \mathrm{e}+00 \\
& 3.00 \mathrm{e}+00 \\
& 2.50 \mathrm{e}+00 \\
& 2.00 \mathrm{e}+00 \\
& 1.51 \mathrm{e}+00 \\
& 1.01 \mathrm{e}+00 \\
& 5.08 \mathrm{e}-01 \\
& 1.00 \mathrm{e}-02
\end{aligned}
$$

[s ]

Particle Residence Time

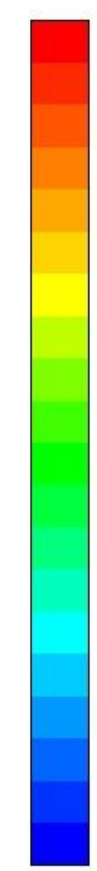

$6.00 \mathrm{e}+01$

$5.70 \mathrm{e}+01$

$5.40 \mathrm{e}+01$

$5.10 \mathrm{e}+01$

$4.80 \mathrm{e}+01$

$4.50 \mathrm{e}+01$

$4.20 \mathrm{e}+01$

$3.90 \mathrm{e}+01$

$3.60 \mathrm{e}+01$

$3.30 \mathrm{e}+01$

$3.00 \mathrm{e}+01$

$2.70 \mathrm{e}+01$

$2.40 \mathrm{e}+01$

$2.10 \mathrm{e}+01$

$1.80 \mathrm{e}+01$

$1.50 \mathrm{e}+01$

$1.20 \mathrm{e}+01$

$9.00 e+00$

$6.01 e+00$

$3.01 \mathrm{e}+00$

$1.00 \mathrm{e}-02$

[s]

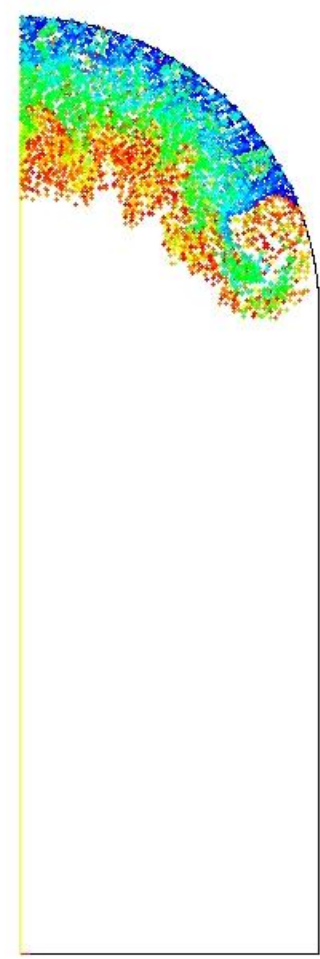

Particle Residence Time

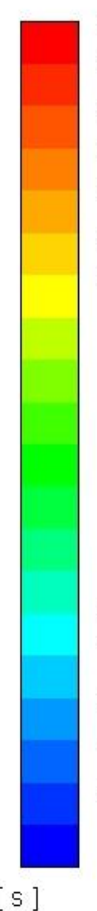

$3.00 \mathrm{e}+01$

$2.85 \mathrm{e}+01$

$2.70 \mathrm{e}+01$

$2.55 \mathrm{e}+01$

$2.40 \mathrm{e}+01$

$2.25 \mathrm{e}+01$

$2.10 \mathrm{e}+01$

$1.95 \mathrm{e}+01$

$1.80 \mathrm{e}+01$

$1.65 e+01$

$1.50 \mathrm{e}+01$

$1.35 e+01$

$1.20 \mathrm{e}+01$

$1.05 e+01$

$9.00 e^{+00}$

$7.51 \mathrm{e}+00$

$6.01 \mathrm{e}+00$

$4.51 e+00$

$3.01 \mathrm{e}+00$

$1.51 \mathrm{e}+00$

$1.00 \mathrm{e}-02$

Particle Residence Time

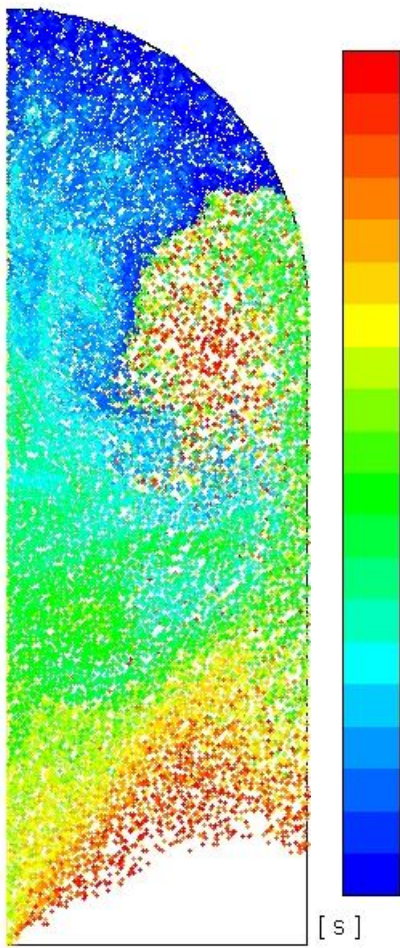

$9.69 e+01$

$9.21 e+01$

$8.72 \mathrm{e}+01$

$8.24 \mathrm{e}+01$

$7.75 e+01$

$7.27 e+01$

$6.79 e+01$

$6.30 e+01$

$5.82 \mathrm{e}+01$

$5.33 \mathrm{e}+01$

$4.85 \mathrm{e}+01$

$4.36 \mathrm{e}+01$

$3.88 \mathrm{e}+01$

$3.39 e+01$

$2.91 \mathrm{e}+01$

$2.42 \mathrm{e}+01$

$1.94 \mathrm{e}+01$

$1.45 e+01$

$9.70 \mathrm{e}+00$

$4.86 e+00$

$1.00 \mathrm{e}-02$

[s]
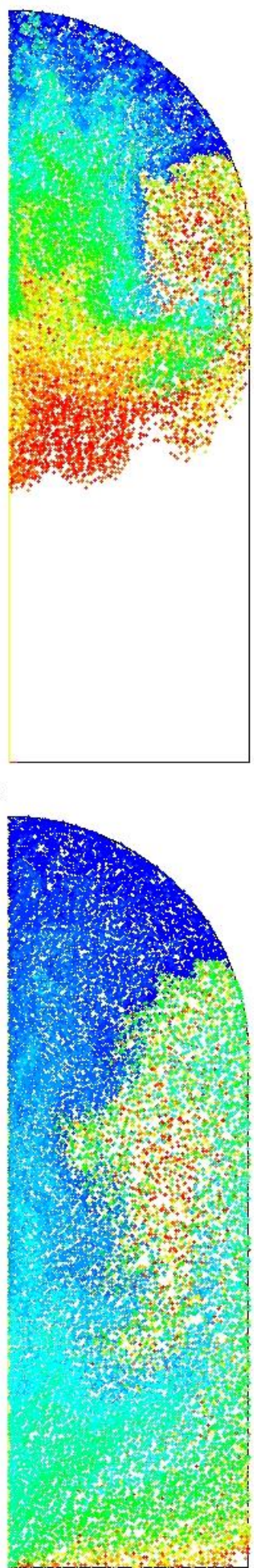

Fig. (6): Time contour of sprayed particles' residence position containment in time intervals of $10,30,60$, and $97 \mathrm{sec}$. related to the second plan 

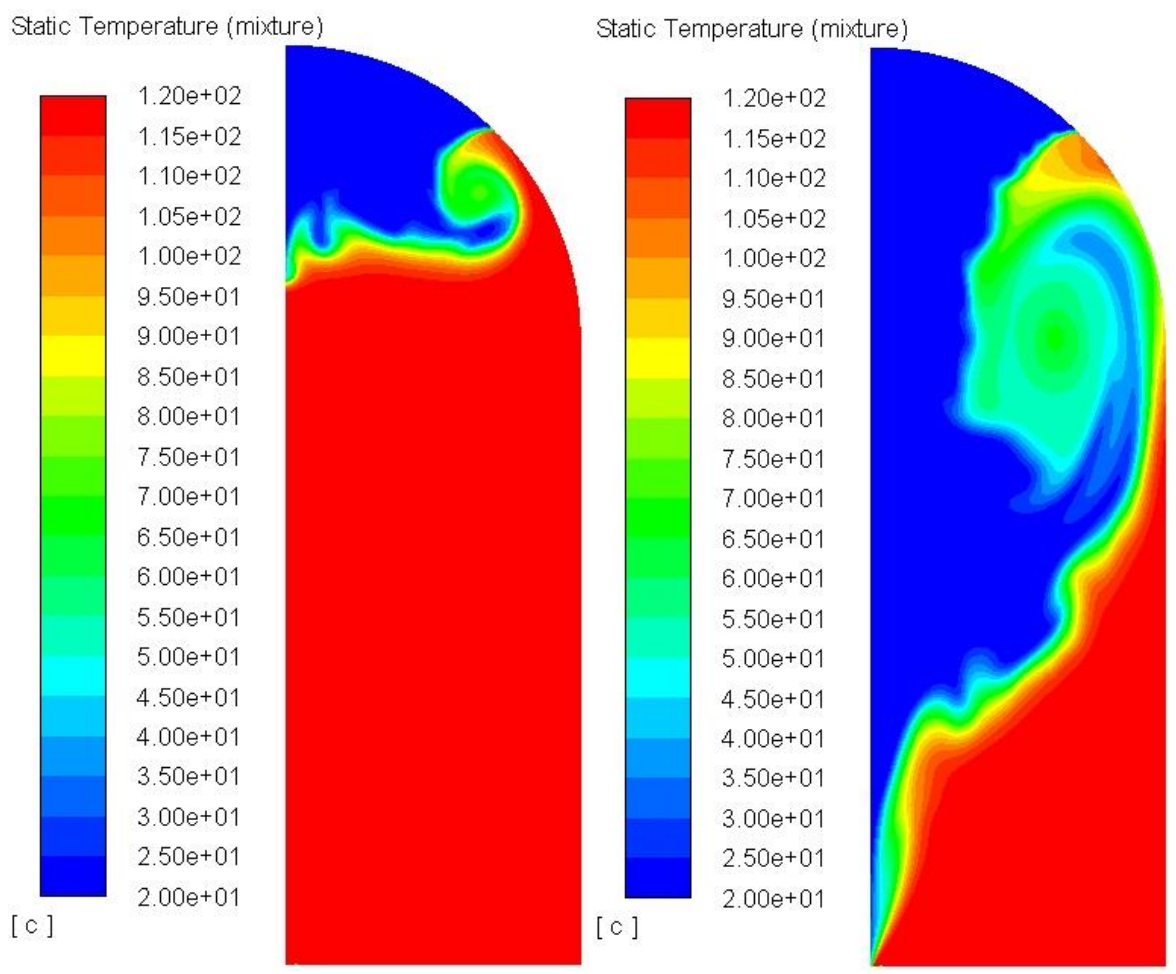

contour-1

Static Temperature (mixture)

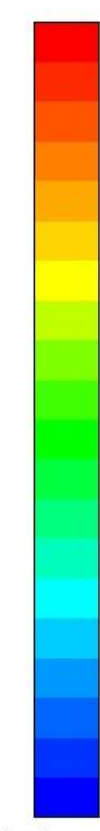
$1.20 \mathrm{e}+02$
$1.15 e+02$
$1.10 e+02$
$1.05 \mathrm{e}+02$
$1.00 e+02$
$9.50 e+01$
$9.00 \mathrm{e}+01$
$8.50 e+01$
$8.00 e+01$
$7.50 \mathrm{e}+01$
$7.00 \mathrm{e}+01$
$6.50 \mathrm{e}+01$
$6.00 \mathrm{e}+01$
$5.50 \mathrm{e}+01$
$5.00 \mathrm{e}+01$
$4.50 \mathrm{e}+01$
$4.00 \mathrm{e}+01$
$3.50 \mathrm{e}+01$
$3.00 e+01$
$2.50 \mathrm{e}+01$
$2.00 e+01$

[c]

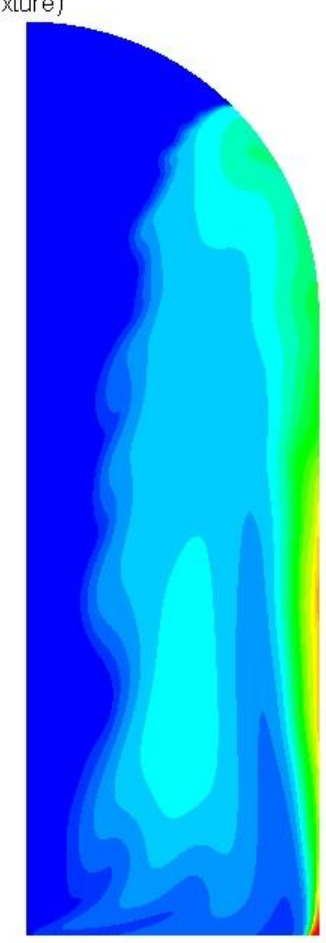

Static Temperature (mixture)

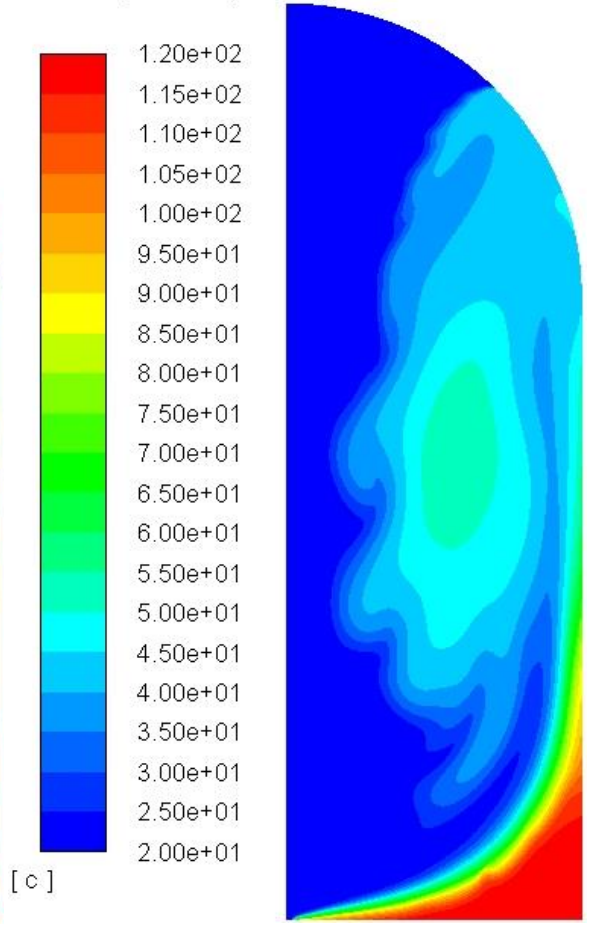

Fig. (7): Internal temperature contour of the containment in time intervals of

$10,40,90$, and $120 \mathrm{sec}$. related to the first plan 


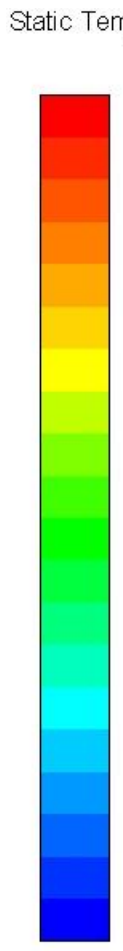

[c]
1. $20 e+02$

$1.15 e+02$

$1.10 e+02$

$1.05 e+02$

$1.00 \mathrm{e}+02$

$9.50 e+01$

$9.00 e+01$

$8.50 \mathrm{e}+01$

$8.00 e+01$

$7.50 e+01$

$7.00 \mathrm{e}+01$

$6.50 \mathrm{e}+01$

$6.00 \mathrm{e}+01$

$5.50 \mathrm{e}+01$

$5.00 e+01$

$4.50 e+01$

$4.00 \mathrm{e}+01$

$3.50 \mathrm{e}+01$

$3.00 \mathrm{e}+01$

$2.50 e+01$

$2.00 e+01$

Static Temperature (mixture)

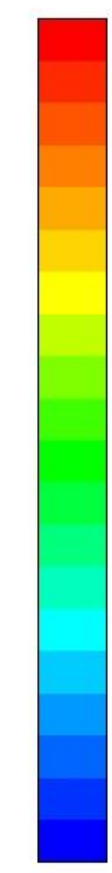

$1.20 e+02$
$1.15 e+02$
$1.10 e+02$
$1.05 e+02$
$1.00 e+02$
$9.50 e+01$
$9.00 e+01$
$8.50 e+01$
$8.00 e+01$
$7.50 e+01$
$7.00 e+01$
$6.50 e+01$
$6.00 e+01$
$5.50 e+01$
$5.00 e+01$
$4.50 e+01$
$4.00 e+01$
$3.50 e+01$
$3.00 e+01$
$2.50 e+01$
$2.00 e+01$

[c]

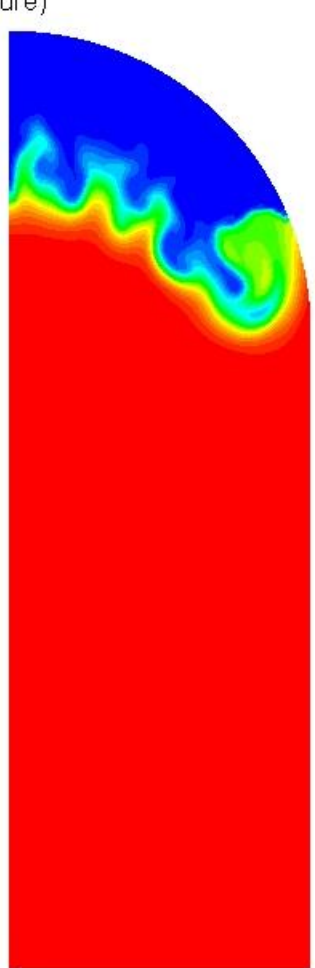

Static Temperature (mixture)

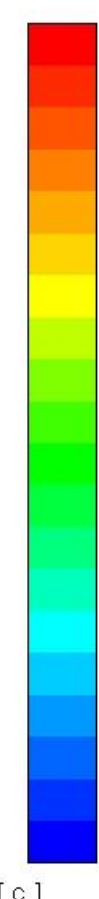

$1.20 \mathrm{e}+02$

$1.15 e+02$

$1.10 \mathrm{e}+02$

$1.05 e+02$

$1.00 e+02$

$9.50 e+01$

$9.00 e+01$

$8.50 e+01$

$8.00 \mathrm{e}+01$

$7.50 e+01$

$7.00 e+01$

$6.50 e+01$

$6.00 \mathrm{e}+01$

$5.50 e+01$

$5.00 e+01$

$4.50 e+01$

$4.00 e+01$

$3.50 e+01$

$3.00 \mathrm{e}+01$

$2.50 \mathrm{e}+01$

$2.00 e+01$

Static Temperature (mixture)
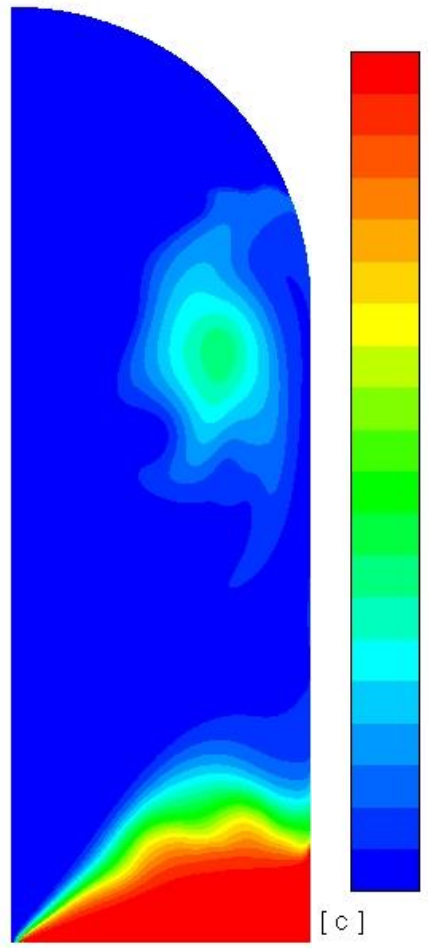

$1.20 e+02$

$1.15 e+02$

1.10e+02

$1.05 e+02$

$9.99 e+01$

$9.49 e+01$

$8.99 e+01$

$8.49 e+01$

$7.99 \mathrm{e}+01$

$7.49 e+01$

$6.99 e+01$

$6.49 e+01$

$5.99 e+01$

$5.49 e+01$

$5.00 \mathrm{e}+01$

$4.50 e+01$

$4.00 e+01$

$3.50 e+01$

$3.00 \mathrm{e}+01$

$2.50 e+01$

$2.00 e+01$

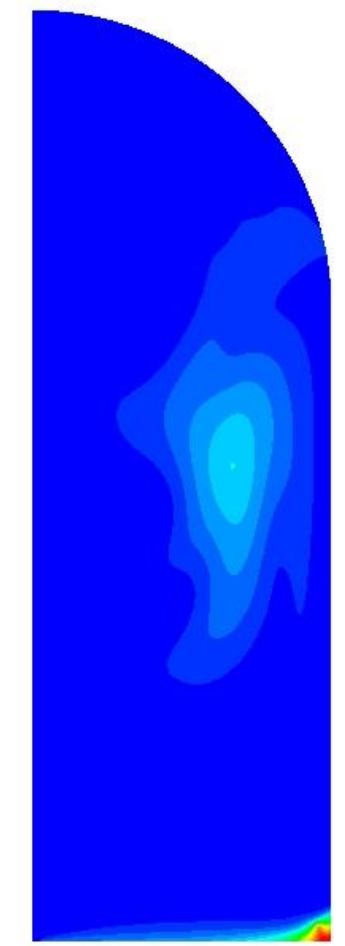

Fig. (8): Internal temperature contour of the containment in time intervals of

\section{$10,30,60$, and 97 sec. related to the second plan}




\section{3-4 Streamline Contour}

Fig. (10) shows streamlines of sprayed particles in containment. Flow turbulence is obvious in presented streamlines. Flow turbulence is more in second plan compared with the first.

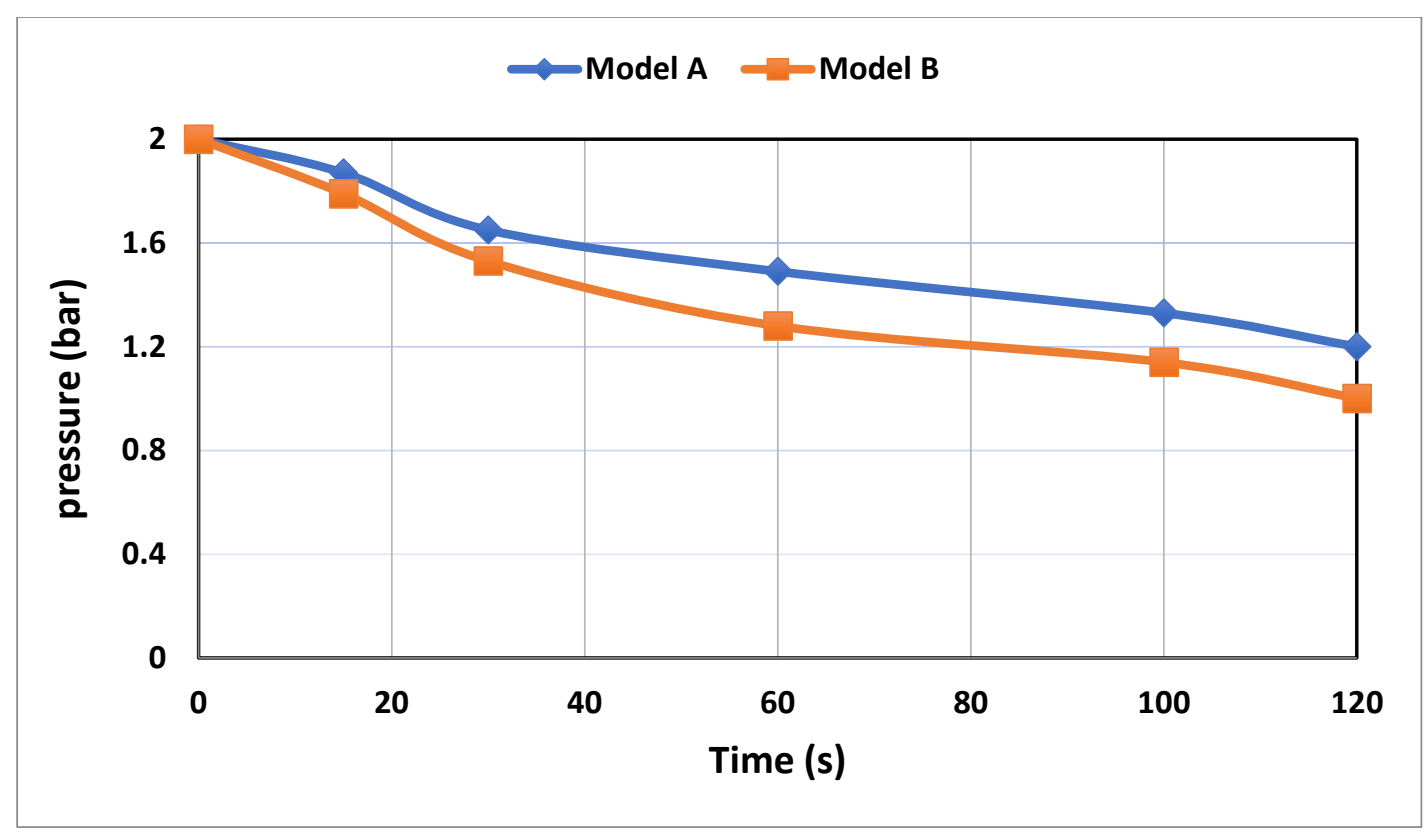

Fig. (9): Containment Pressure in both simulated model
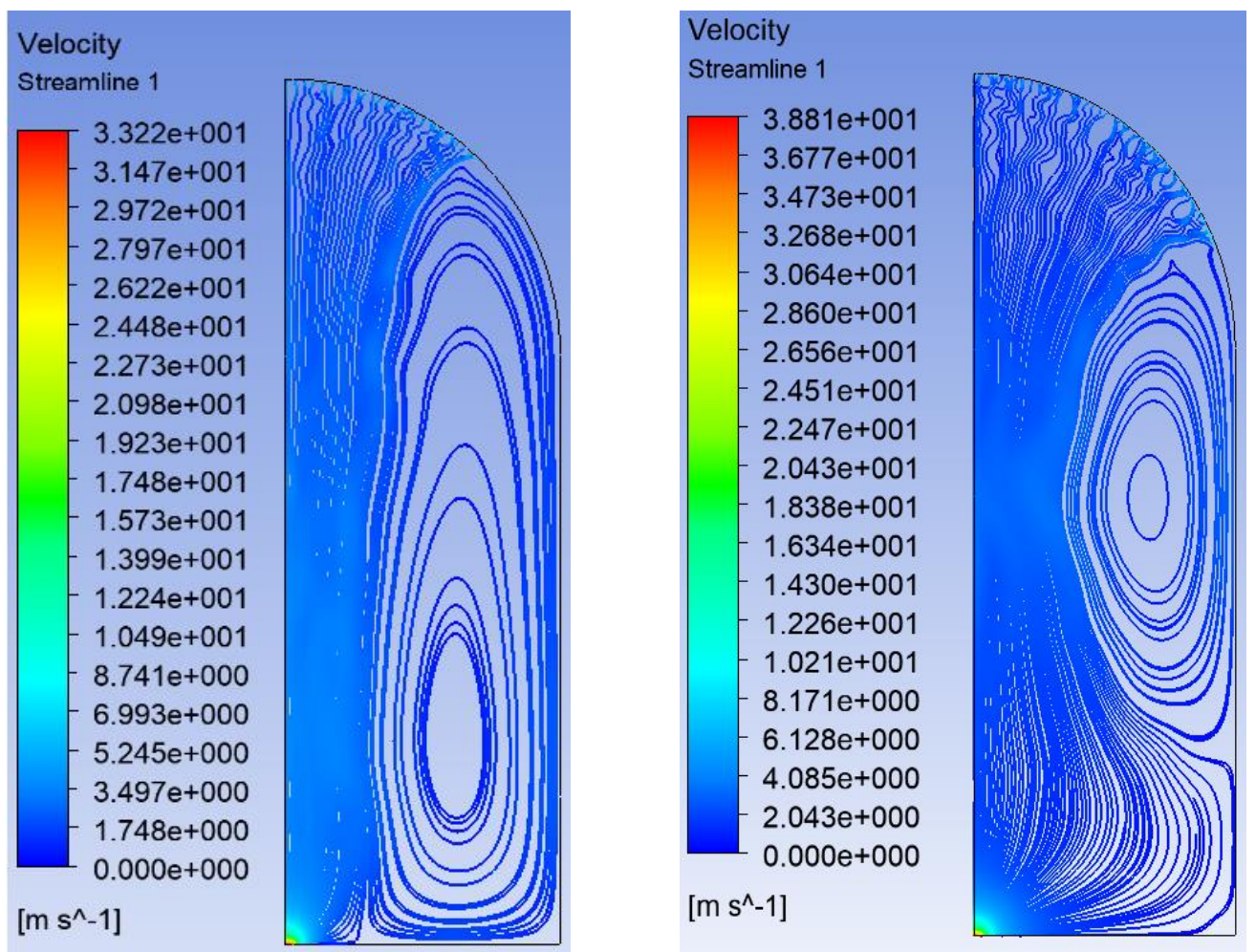

Fig. (10): Streamline Contour in both simulated model ( left (first plan), right (second plan)) 


\section{3-5 Velocity vectors}

Velocity vectors at the inlet of reactor containment are shown in Fig. (11). The velocity vectors in the bottom outlet of the reactor concrete tank are given in
Fig. (12) . As shown in these figures, streamlines around sprays are turbulent. Also, in the middle part of the concrete tank near the wall, streamlines are found to be whirepool.

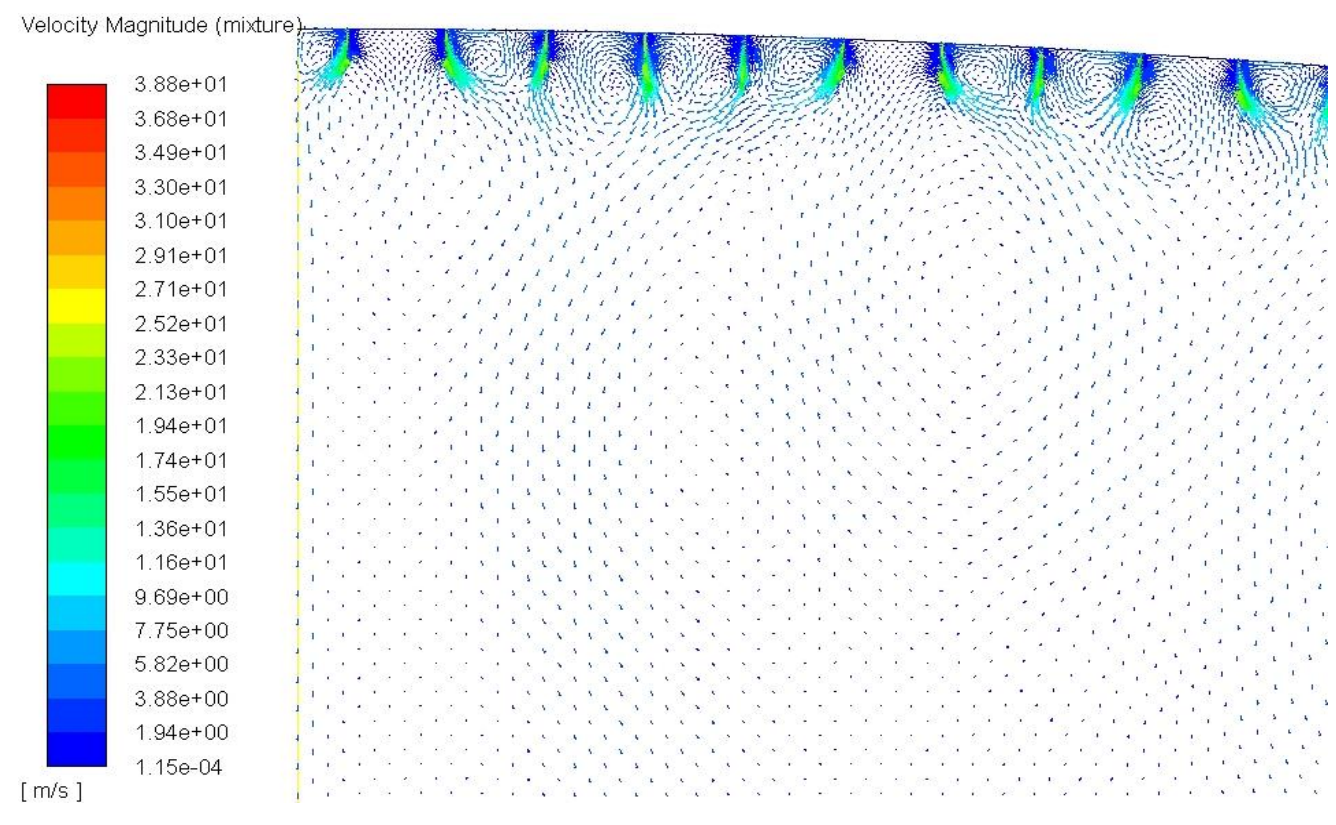

Fig. (11): Velocity vectors at the inlet of reactor containment

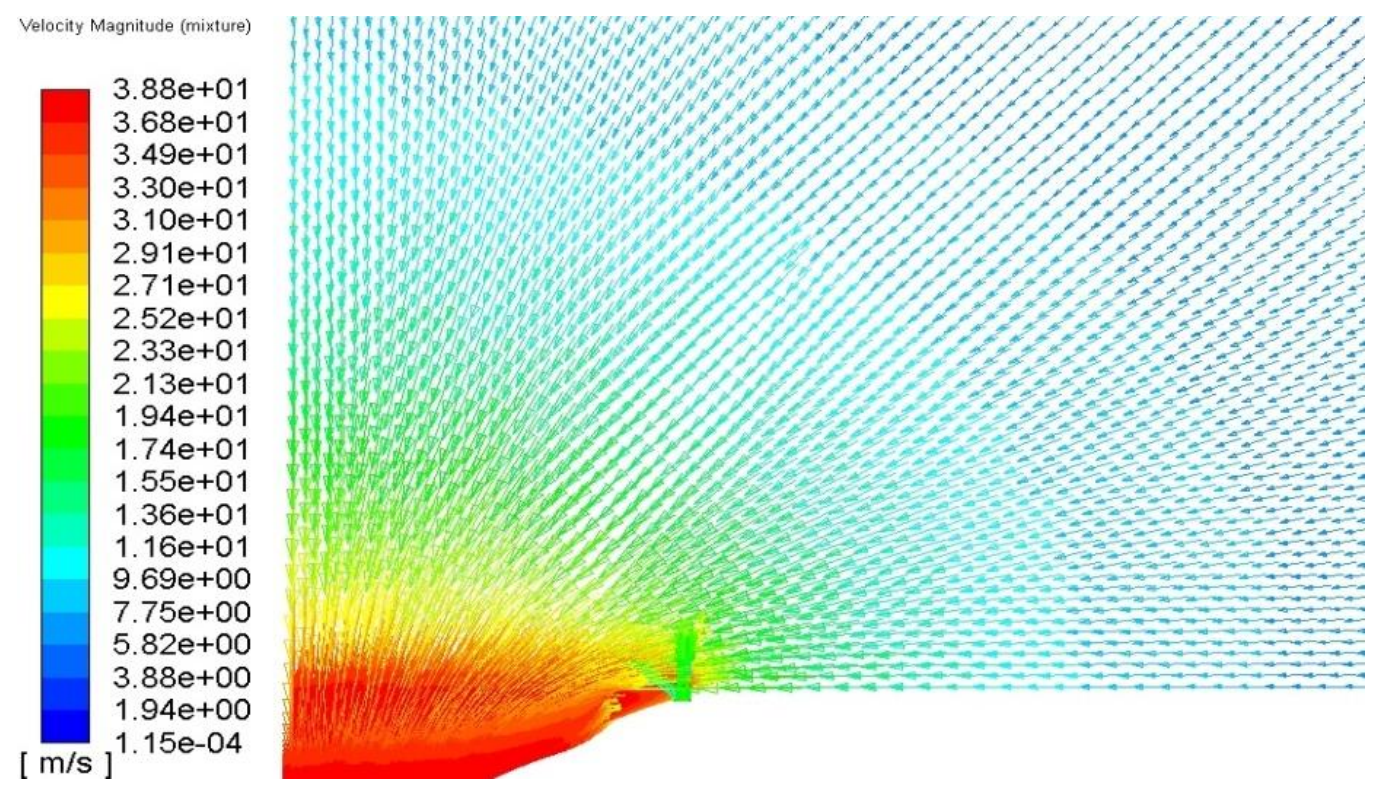

Fig. (12): Velocity vectors in the bottom outlet of reactor containment 


\section{CONCLUSION}

Transient and thermal-hydraulic results of temperature and pressure distribution and particle residence in 250 functioning sprays for nuclear reactor containment are presented. The simulation of the research topic using ANSYS FLUENT software, two phase flow condition and 250 spray was very complex and is presented for the first time. Due to the complexity of the two-phase simulation of the research topic, a twodimensional model was selected. 250 spray contours in height of 6 meters from the upper part of reactor tank (first plan) in time intervals of 10,40, 90, and 120 seconds and 250 spray contours in height of 20 meters from the upper part of reactor tank (second plan) in time intervals of 10, 30, 60, and 97 seconds are studied. Studying sprays' function as an important component of reactor emergency safety system in reducing temperature and pressure in the concrete tank is of utmost importance in preventing disasters. Results of this study show that spray system has been able to effectively reduce temperature and pressure of containment in an emergency condition. In the first design, the temperature decrease was not uniform and steam temperature reduction has not been done in the lower part of the containment. By increasing the height of the spray system from the top of containment, the performance of the spray system improves and the temperature of the hot steam inside the concrete chamber decreases uniformly. Of the two presented plans, the second one has had a better performance, in a way that temperature and pressure are decreased spending less time. Temperature distribution in the second plan has been more uniform after spray function compared to the first plan, which is due to more even distribution of sprayed droplets. Proper arrangement and design of sprays play an important role in reducing the temperature and pressure of the nuclear containment optimally.

\section{REFERENCES}

[1] Lin.H, AYYASWAMYLin.P.S ,1986, heat transfer of a nuclear reactor containment spray drop, Nuclear Engineering and Design, 101,p 137-148

[2] Babic, M and Kljenak, I., 2007. CFD spray simulations for nuclear reactor safety applications with lagrangian approach for droplet modeling, International Conference Nuclear Energy for New Europe, p. 13, Portoroz, Slovenia, September .

[3] Babic, M., Kljenak, I., 2009. Simulations of TOSQAN containment spray tests with combined Eulerian CFD and droplet-tracking modelling. Nucl. Eng. Des.239, 708-721
[4] Malet, J., Gelain, T., Mimouni, S., Manzini, G., Arndt, S., Klein-Hessling, W., Xu, Z.,Povilaitis, M., Kubisova, L., Parduba, Z., Paci, S., Siccama, N.B., Stempniewicz,M.H., 2011b. Spray model validation on single droplet heat and mass transfers for containment applications - SARNET 2 benchmark. In: The 14th International Topical Meeting on Nuclear Reactor Thermal hydraulics, NURETH-14, Toronto, Canada, September 25-30

[5] Malet.J, Foissac.A, Vayaboury.A, Gélain.T, Mimouni.S, 2012, Numerical study on the influence of simplified spray boundary conditions for the characterization of large industrial safety spray systems used in nuclear reactors.

[6] Hesham Elbakhshawangy., 2020, Effect of Tilting Angle on Natural Convection Heat Transfer from a Cylinder Suspended in Stagnant Water, Arab Journal of Nuclear Sciences and Applications, Vol. $53,2,56-67$

[7] Malet, J., Blumenfeld, L., Arndt, S., Babic, M., Bentaib, A., Dabbene, F., Kostka, P.,Mimouni, S., Movahed, M., Paci, S., Parduba, Z., Travis, J., Urbonavicius, E., 2011a.Sprays in containment: final results of the SARNET spray benchmark. Nucl. Eng.Des. 241, 2162-2217.

[8] Malet.J, Parduba.Z, Mimouni.S, Travis.J, 2014, Achievements of spray activities in nuclear reactor containments durin gthe last decade,Annals of Nuclear Energy 74 . 134-142

[9] Xing. J, Song. D, Yixing.W,2016, HPR1000: Advanced Pressurized Water Reactor with Active and Passive Safety, Engineering 2 (2016) 79-87

[10] Pättikangas, $T$ and Huhtanen R ,2016, CFD simulations of preliminary single spray experiments, 2016,VTT Technical Research Centre of Finland

[11] Kaltenbach, C., Laurien, E., 2018. CFD simulation of spray cooling in the model containment THAI, Nucl. Eng. Des.328, 359-371

[12] Hu HT, Lin JX., 2016. Ultimate analysis of PWR prestressed concrete containment under long-term prestressing loss. Annals of Nuclear Energy $87,500-510$

[13] Collier, J.G.; Thome, J.R., 1994. Convective Boiling and Condensation, 3rd ed.; Oxford University Press:Oxford, UK.

[14] Adel Lotfy Ismail., 2020, The Models Used in Predicting Steam Condensation Occuring duringNuclear Reactor Loss of Coolant Accident, Arab Journal of Nuclear Sciences and Applications, Vol.53, 1, 137-148 